2. Very little gradation of response in growth was observed with the daily doses of 25, 50 and $100 \mu \mathrm{g}$ pantothenic acid.

3. Male rats were more sensitive than female rats in their growth response to pantothenic acid.

4. Although a daily dose of $25 \mu \mathrm{g}$ pantothenic acid was almost adequate for growth, it did not completely prevent the greying of the black parts of the coat.

5. In rats deprived of pantothenic acid the red-cell count increased and the cells were microcytic and hypochromic. There was no anaemia.

6. In pantothenic-acid deficiency the number of white cells did not change.

\title{
REFERENCES
}

Ashburn, L. L., Daft, F. S. \& Faulkner, R. R. (1947). Blood, 2, 45 I.

Bacon, J. S. D. \& Jenkins, G. N. (1943). Biochem. F. 37, 492.

Batchen, J. M., Cheesman, E. M., Copping, A. M. \& Trusler, A. D. (1955). Brit. F. Nutr. 9, 49.

Bell, G. H. (1952). Experimental Physiology, p. 284. Glasgow: John Smith and Son (Glasgow) Ltd. Copping, A. M. (1943a). Biochem. F. 37, 12.

Copping, A. M. (r943b). Unpublished.

Copping, A. M., Crowe, P. J. \& Pond, V. R. G. (195r). Brit. F. Nutr. 5, 68.

Daft, F. S., Kornberg, A., Ashburn, L. L. \& Sebrell, W. H. (1945). Publ. Hlth Rep., Wash., 60, 1201. Frost, D. V. (1948). Physiol. Rev. 28, 368.

King, E. J., Wootton, I. D. P., Donaldson, R., Sisson, R. B. \& Macfarlane, R. G. (1948). Lancet, 255, 971 .

King, 'T. E., Strong, F. M. \& Cheldelin, V. H. (1950). F. Nutr. 42, 195.

Lih, H., King, T. E., Higgins, H., Baumann, C. A. \& Strong, F. M. (195 I). 7. Nutr. 44, 36 r.

Morgan, A. F. (195I). Vitam. Eं Horm. 9, I6r.

Unna, K. (1940). F. Nutr. 20, 565.

\section{Effect of pantothenic-acid deficiency on certain organs of the rat}

\author{
By CYNTHIA D. COMBRIDGE AND ALICE M. COPPING \\ Departments of Physiology and Nutrition, Queen Elizabeth College \\ (University of London), Campden Hill Road, London W. 8
}

(Received 29 August 1956)

Since changes had been observed in some organs of the pyridoxine-deficient rat (Combridge, I956), it was thought that it would be interesting to examine organs from the pantothenic acid-deficient rat and to compare the two sets of results.

\section{EXPERIMENTAL}

The forty-seven rats were from series $C_{15}$, described in the previous paper (Blunt, Cheesman \& Copping, 1957), where details of the treatment will be found. After the blood samples had been taken, the rats were killed by opening the thorax. Portions of 
the liver, kidney, duodenum, heart and both adrenal glands were placed, in that order, in fixing fluid. Liver, kidney and one adrenal gland were fixed in $10 \%(\mathrm{v} / \mathrm{v})$ formaldehyde in $0.9 \% \mathrm{NaCl}$, and frozen sections of each were stained with Sudan III. The liver and kidney were counterstained with iron haematoxylin. The remaining adrenal gland, the heart and duodenum were fixed in Susa's fluid and stained with Scott's haematoxylin and dilute Biebrich scarlet. Unfortunately, it was not possible to weigh the adrenal glands or other organs.

\section{RESULTS}

The heart, duodenum, liver and kidney showed no gross changes in histological structure that could be related to the doses of pantothenic acid. The livers of one or two rats in each group showed small amounts of fat in the cells of the portal region. It was presumably due to the diet consumed shortly before death and in no way related to the pantothenic-acid content of the diet. The adrenal glands, however, did show changes in the pantothenic acid-deficient group and in the group receiving a small curative dose.

The sections of some adrenal glands showed an enlarged zona glomerulosa. Most of such glands were found to belong to rats having no dose of pantothenic acid or a small restorative dose after deprivation for 7-I I weeks. A small amount of haemorrhage was observed also in the adrenal glands of some rats, stained with haematoxylin and dilute Biebrich scarlet. The distribution of haemorrhagic adrenal glands was as follows: seven out of nine pantothenic acid-deficient rats, three out of eight rats having $25 \mu \mathrm{g}$ after previous deprivation, one or two out of each group of eight rats of other groups.

In the sections of adrenal glands stained with Sudan III, there was an increase in the amount of lipid in the zona glomerulosa of rats deprived of pantothenic acid (Pl. I). In rats deprived of pantothenic acid for $7^{-1} \mathrm{I}$ weeks and then given a curative dose of $25 \mu \mathrm{g}$ for 4 weeks there were increased amounts of lipid in both the zona glomerulosa and the zona fasciculata of the cortex (Pl. I).

No differences were observed between males and females in any organ studied.

\section{DISCUSSION}

The absence of lipid in the livers of the pantothenic acid-deficient rats of the present series is in agreement with the findings of other workers (Morgan, I95 I, p. I89). This finding is, however, different from that of the centrilobular accumulations of lipid in the livers of pyridoxine-deficient rats (Combridge, 1956).

The changes in the adrenals of our animals should be compared with the results of Ashburn, Daft \& Faulkner (1947) on pantothenic-acid deficiency. They found marked depletion of cortical lipids, occasionally with haemorrhage and necrosis of the adrenals. Our experiments confirm the occurrence of adrenal haemorrhage in pantothenic-acid deficiency, but show increased, not decreased, amounts of lipid in the zona glomerulosa of the adrenal cortex. The blood picture observed by Blunt et al. (1957) differed from that described by Ashburn et al. (1947), so that it is not surprising to find histological pictures differing also. The differences may be due to differences in 
CYNTHIA D. COMBRIDGE AND ALICE M. COPPING

Plate I

PANTOTHENIC ACID AND RAT ORGANS
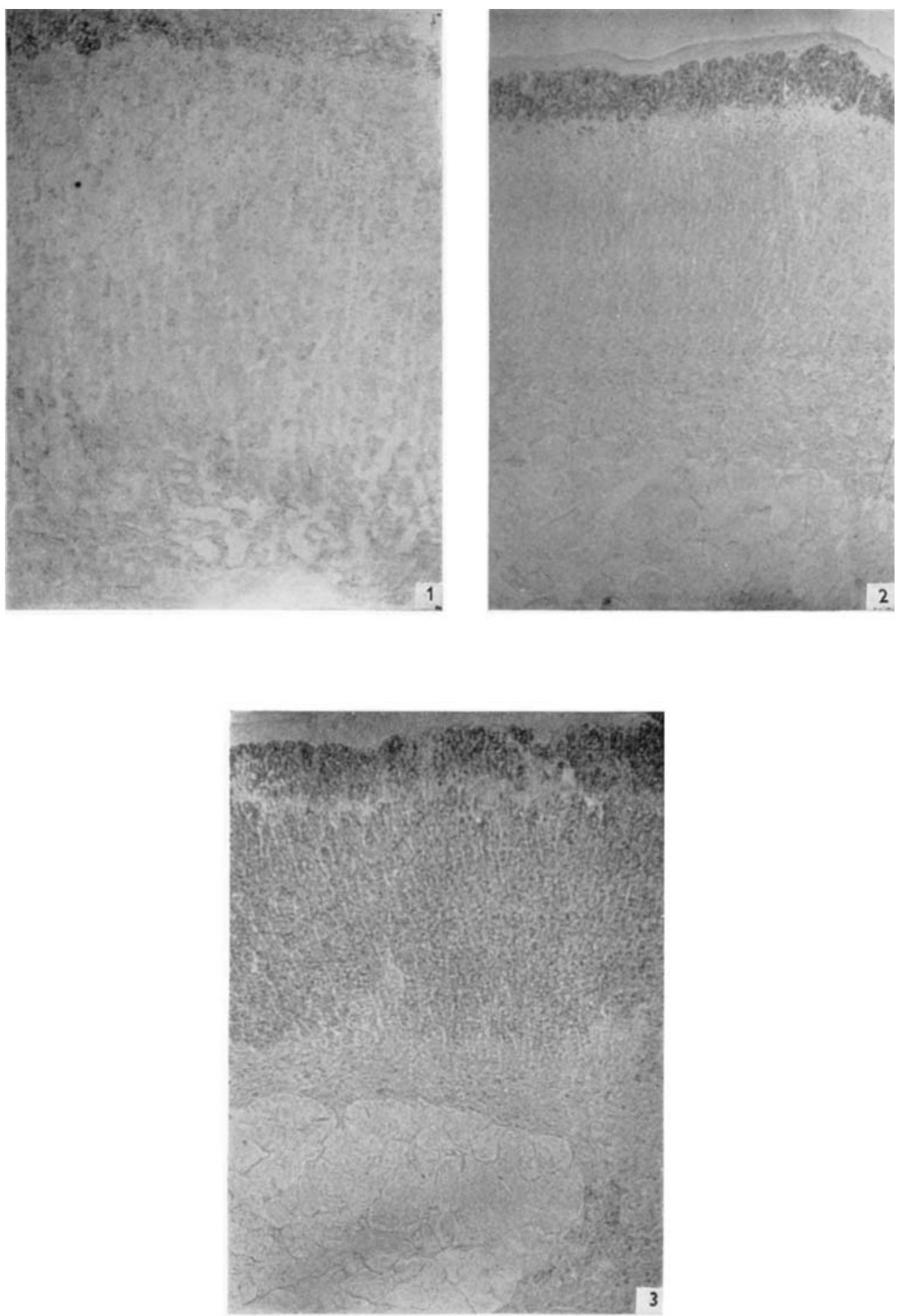

British Yournal of Nutrition, Vol. I I, No. I 
the diets used, notably the lack of folic acid and vitamin $B_{12}$ in the purified diet of Ashburn et al.

The rats of Deane \& McKibbin (1946) also showed a rapid and complete loss of sudanophil lipids from the zona fasciculata as pantothenic-acid deficiency progressed, as well as signs of haemorrhage. Their diets were deficient in folic acid, biotin and vitamin $\mathrm{B}_{12}$, however, and are therefore not strictly comparable with those used in our experiments.

The increased amounts of lipid seen in the zona glomerulosa of our pantothenic acid-deficient rats and those given a small curative dose may indicate increased manufacture or storage of aldosterone, deoxycorticosterone or a precursor such as cholesterol. Studies by Winters, Schultz \& Krehl (1952a, $b$ ) of adrenal cortical function in rats deprived of pantothenic acid suggested the importance of pantothenic acid as part of coenzyme $A$ in the biosynthesis of steroid hormones in the adrenal gland. A possible explanation of the accumulation of lipids in the zona glomerulosa might be a mobilization of available resources to meet the stress of deprivation of the essential component of the coenzyme system.

The marked increase of sudanophilic lipid in the zona fasciculata in rats deprived of pantothenic acid for 7-I I weeks and then given $25 \mu \mathrm{g}$ daily for 4 weeks could indicate an increased manufacture or storage of cortisone or a related substance. The lack of lipid in the zona fasciculata in deprived rats may be due to decreased stores of cortisone. This finding would agree also with that of Winters et al. (1952a). The solution of the problem requires simultaneous study of functional and histological changes in the adrenal cortex.

The adrenal glands of pantothenic acid-deficient rats differed markedly from those of pyridoxine-deficient rats of the same strain. In pyridoxine-deficient rats an increased content of lipid was found in the zona fasciculata, whereas that of the zona glomerulosa was unchanged (Combridge, 1956). The two markedly different sets of findings would seem to refute the suggestion that the inanition resulting from a deficient diet was the cause of the adrenal changes in both series, since both pantothenic acid-deficient and pyridoxine-deficient rats were suffering from extreme inanition.

\section{EXPLANATION OF PLATE}

Frozen sections, $5 \mu$ thick, of adrenal glands stained with Sudan III. $\times$ r2o.

I. From a rat on the laboratory stock diet. Small quantities of dark-staining lipid are visible in the zona glomerulosa and in the zona fasciculata.

2. From a rat on a diet deficient in pantothenic acid. The increased size and lipid content of the zona glomerulosa are clearly seen.

3. From a rat fed on a diet deficient in pantothenic acid for 7-I I weeks, then given $25 \mu \mathrm{g}$ daily for 4 weeks. Increased quantities of lipid appear in both the zona glomerulosa and the zona fasciculata.

\section{SUMMARY}

I. Organs from forty-seven rats on purified diets with and without pantothenic acid, and on a stock diet, were examined. They included the heart, liver, kidney and adrenals. 
2. Marked changes were seen only in the adrenal glands, where the size and lipid content of the zona glomerulosa were increased in rats totally deprived of pantothenic acid and in those having small curative doses. Increased lipid was found also in the zona fasciculata of the animals recovering from deprivation. These changes are contrasted with those seen in the adrenal glands of pyridoxine-deficient rats.

The authors wish to express their sincere thanks to Mrs A. D. Blunt and Mrs E. Cheesman who helped in the preparation of the sections, and to $\mathrm{Mr}$ G. Willoughby who took the photographs.

\title{
REFERENCES
}

Ashburn, H., Daft, F. S. \& Faulkner, R. R. (1947). Blood, 2, 45 I.

Blunt, A. D., Cheesman, E. M. \& Copping, A. M. (1957). Brit. F. Nutr. I1, 62.

Combridge, C. D. (1956). Brit. F. Nutr. ro, 347.

Deane, H. W. \& McKibbin, J. M. (1946). Endocrinology, 38, 385 .

Morgan, A. F. (1951). Vitam. \&ั Horm. 9, 161.

Winters, R. W., Schultz, R. B. \& Krehl, W. A. (1952a). Endocrinology, 50, 377.

Winters, R. W., Schultz, R. B. \& Krehl, W. A. (1952b). Endocrinology, 50, $3^{88}$.

\section{Further studies on antibiotic and copper supplements for fattening pigs*}

\author{
By R. S. BARBER, R. BRAUDE, K. G. MITCHELL \\ AND J. A. F. ROOK \\ National Institute for Research in Dairying, Shinfield, near Reading \\ AND J. G. ROWELL \\ Agricultural Research Council Statistics Group, \\ School of Agriculture, Cambridge \\ (Received 24 September 1956)
}

Barber, Braude, Mitchell \& Cassidy (1955) and Bowler, Braude, Campbell, CraddockTurnbull, Fieldsend, Griffiths, Lucas, Mitchell, Nickalls \& Taylor (1955) reported that the growth rate of pigs was improved when their normal fattening ration was supplemented with a high-copper mineral mixture. Later, Barber, Braude \& Mitchell (1955) showed that the addition of $0.1 \%$ copper sulphate (supplying 250 p.p.m. copper) to a fattening-pig diet was as effective as chlorotetracycline (aureomycin) in increasing growth rate. The findings suggested that the faster growth of the copper-supplemented pigs was due to improved food utilization rather than increased food consumption.

Three further experiments are reported here, in which the effects of copper and antibiotic supplements on growth rate, food conversion, food consumption, carcass

* Read in part before The Nutrition Society on 26 May I956 (Barber, Braude, Mitchell, Rook \& Rowell, 1956). 